\title{
Diseases and histological normality of the renal glomerulus: a clinicopathological study
}

\author{
WILLIAM LAWLER, P. TARPEY, GEORGE WILLIAMS ${ }^{1}$, E. JOAN ACHESON, \\ AND N. P. MALLICK \\ From the Departments of Pathology and Renal Medicine, Manchester Royal Infirmary and Medical School, \\ University of Manchester
}

SYNOPSIS Thirty-seven percutaneous renal biopsies showing no significant abnormalities on light microscopy were studied electron optically and by immunofluorescence when available. Assessment $\dot{\infty}_{\infty}^{\omega}$ of the pathological material was followed by analysis of the patients' clinical notes, and a clinicopathological correlation was carried out.

Twenty-three patients fulfilled the clinical criteria of minimal change disease; 10 did not behave $\vec{z}$ clinically as minimal change and showed immune complex deposition; two had benign recurrent haematuria; and two had myelomatosis.

Our study shows that if diagnosis is based solely on the light microscope appearances of renal $/$ biopsy, diseases other than minimal change are likely to be overlooked. Accuracy of diagnosis in structural terms requires additional immunofluorescence and electron microscopic study; final clinical diagnosis also requires careful follow-up, and repeat biopsy may be necessary.

For over 60 years it has been known that there are patients, both children and adults, with the nephrotic syndrome in whom no significant glomerular changes can be seen by light microscopy of biopsy specimens. These patients have constituted the problem of minimal change glomerulonephritis (lipoid nephrosis, foot process disease, 'nil' disease), in which it was found difficult to equate clinical severity with apparently normal histological glomerular appearances (Robson, 1972).

The introduction of electron microscopy showed that in minimal change glomerulonephritis there is partial or complete fusion of the epithelial cell foot processes (Farquhar et al, $1957 \mathrm{a}$ and b; Folli et al, 1958; Movat and McGregor, 1959; Bencosme and Bergman, 1962), and that this is the one consistent morphological abnormality (Pollak et al, 1968; Spargo and Seymour, 1972; Jao et al, 1973).

However, it has recently been realized that other glomerular lesions not readily detectable by light microscopy may cause proteinuria or the nephrotic syndrome (Hopper et al, 1970; Muehrcke and Pirani, 1972; Jao et al, 1973; Hyman and Burkholder, 1974).

We have therefore reviewed renal biopsy specimens

1Requests for reprints to $G$. W.

Received for publication 4 October 1975 submitted over a seven-year period and selected $\stackrel{\varrho}{\rightarrow}$ those in which the glomeruli showed no significant $\frac{\text { 3 }}{3}$ histological abnormality for detailed study by electron microscopy, and immunofluorescence when available. Our findings were subsequently correlated with the clinical findings.

\section{Material and Methods}

A total of 308 percutaneous biopsies were reviewed. Of these, $37(12.0 \%)$ were considered as showing histologically normal glomeruli or, at most, marginalo increases in mesangial cells and/or matrix. All biopsy specimens contained a minimum of five untraumatized or glomeruli, the majority more than 10 .

From 28 of these cases, processed material was N studied electron optically; in 12 cases, electron $\omega$ microscopy was augmented by immunofluorescence studies. Seven patients underwent repeat biopsies.

Assessment of the pathological material wasc followed by analysis of the patients' clinical notes, and a clinicopathological correlation was carried out.

\section{TECHNIQUES}

Immediately on removal of the biopsy cores, smallo fragments were cut from both ends and fixed for electron microscopy. The remainder was bisected, 
half being used for light microscopy and half for immunofluorescence studies.

\section{Light Microscopy}

Tissue was fixed in mercuric formalin, dehydrated, and embedded in Paraplast. Sections of $2 \mathrm{~mm}$ maximum thickness were routinely stained with haematoxylin and eosin (H and $\mathrm{E}$ ), periodic acid-Schiff (PAS), Martius-scarlet-blue (MSB), and methenamine silver (MeS).

\section{2a Transmission Electron Microscopy}

Primary fixation was in buffered $2.5 \%$ glutaraldehyde, followed by repeated washing in cacodylate buffer. After post-fixation in buffered osmium tetroxide, the tissue was dehydrated and embedded in Araldite. $0.5 \mathrm{~mm}$ thick sections were stained with alkaline toluidine blue for tissue recognition, and thin sections containing glomeruli were mounted on grids, double stained with uranyl acetate/lead citrate, and examined electron optically.

\section{2b Scanning Electron Microscopy}

Small fragments of tissue were fixed for 4 hours in $2.5 \%$ glutaraldehyde followed by washing in three changes of cacodylate buffer over 24 hours and storage in buffer wash at $4^{\circ} \mathrm{C}$. After dehydration in graded acetones, ranging from $30 \%$ to $100 \%$ in $10 \%$ increments, the tissue was critical point dried from liquid $\mathrm{CO}_{2}$. Dried tissue blocks were fastened to stubs with colloidal silver and coated with gold in a Polaron Sputter coater. Coated blocks were examined in a Cambridge S4-10 SEM at a gun potential of $20 \mathrm{kV}$.

\section{Immunofiuorescence}

$4 \mathrm{~mm}$ thick cryostat sections were incubated for $\mathbf{3 0}$ minutes with commercially prepared FITC conjugated antisera to IgA, IgG, IgM, IgE, fibrinogen, and the $\mathrm{C}_{3}$ fraction of complement, and then viewed under ultraviolet excitation. Control sections were pretreated with unconjugated antihuman antiserum, the specificity of which was checked at intervals by immunoelectrophoresis.

\section{Results}

\section{LIGHT MICROSCOPY}

Glomerular appearances ranged from normal to mild prominence of mesangial components only (figs 1 and 2).

\section{A TRANSMISSION ELECTRON MICROSCOPY (TEM)}

Of the 28 cases studied, 17 showed significant fusion of the epithelial cell foot processes (fig 3), often with

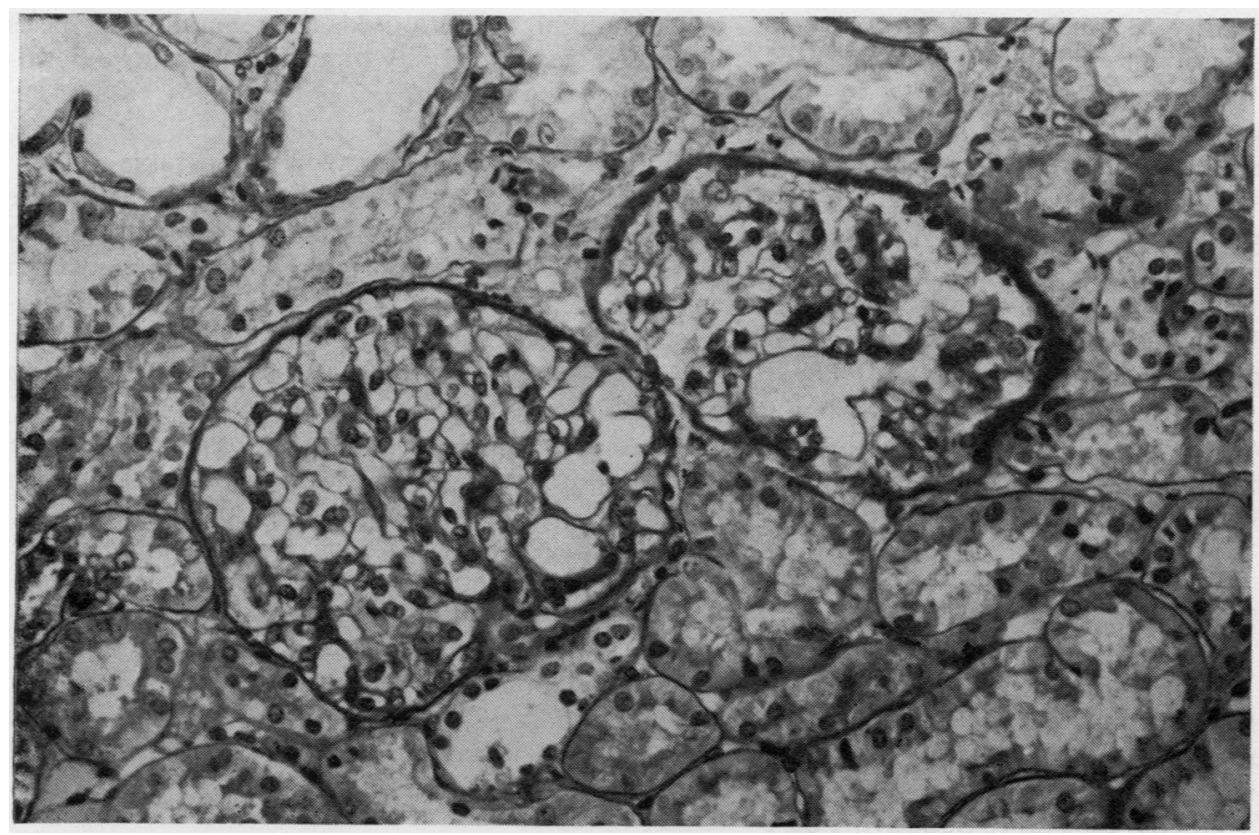

Fig 1 Histologically normal glomeruli in first biopsy specimen from patient 4 (cf figs 11 and 12). $P A S \times 350$ 


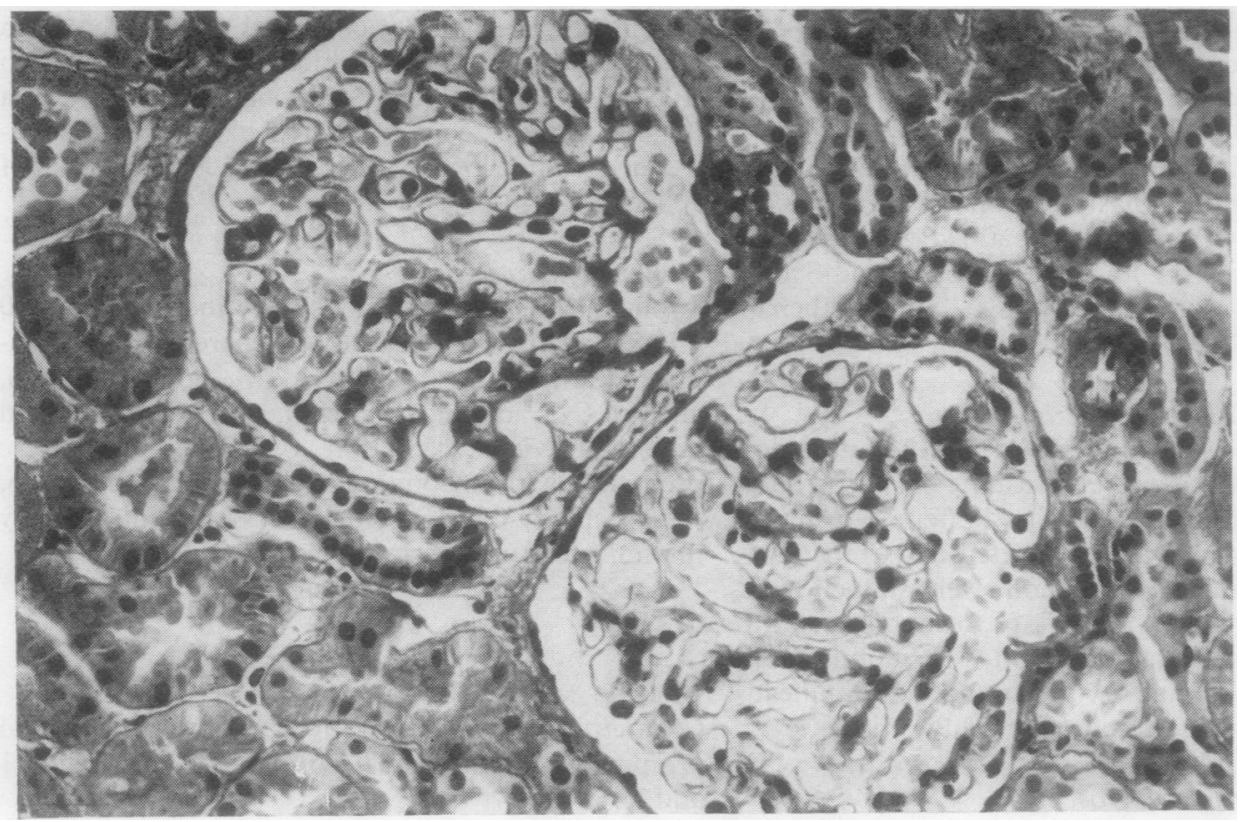

Fig 2 Slight prominence of mesangial areas in otherwise normal glomeruli from patient with foot process disease. $M S B \times 400$

a slightly increased vesiculation of visceral epithelial cells. None disclosed granular or fibrillar deposits in, or other abnormality of, their capillary basement membranes or mesangial areas. These cases were categorized as 'foot process disease' (FPD).

In eight cases, granular electron dense deposits, indicating immune complexes, were present in focally thickened basement membranes. These complexes, though not numerous, were predominantly epimembranous in distribution (fig 4) but occasionally involved the mesangia or adjacent basement membranes (fig 5). On this basis, these were classified as immune complex disease (ICD).

In two cases (28 and 34), fibrillar material similar to amyloid with a focal epimembranous and mesangial distribution was present (fig 6).

In one case (11), glomeruli appeared normal.

\section{2b SCANNING ELECTRON MICROSCOPY (SEM)}

Limited tissue availability from the renal cores restricted SEM to a few specimens only. The main advantage of this technique lay in providing high resolution topographical views of glomerular structure in which fusion of epithelial foot processes and collapse of epithelial cells on to underlying basement membranes were seen to advantage (figs 7 and 8).
3 IMMUNOFLUORESCENCE (IF)

This was available in 12 cases. Of these, six werê, negative to all antisera used; the remaining six casesdisclosed weak positivity to a range of labelled antif sera (figs 9 and 10).

\section{PATHOLOGICAL CLASSIFICATION (table I)}

Based on EM and IF evidence, 17 of the 37 cases were classified as FPD. Extensive EM study of this group failed to reveal immune complex deposists withir glomeruli, and IF studies for localizing immuno오 globulins, when performed, were negative.

Nine cases were classified as ICD. Eight of them? showed electron dense granular deposits, and IF when done, was positive; in one case (25), IF was weakly positive, but no material was available fo EM.

One case (11), from which IF was not available was classified as normal on EM evidence only.

Two cases (28 and 34), although negative to al fluorescent antisera, were classified as 'amyloiff disease', as already described.

In eight cases, classification was not possible because of insufficient tissue or unavailability of EN or IF evidence.

The clinical notes and follow-up records of the 39 


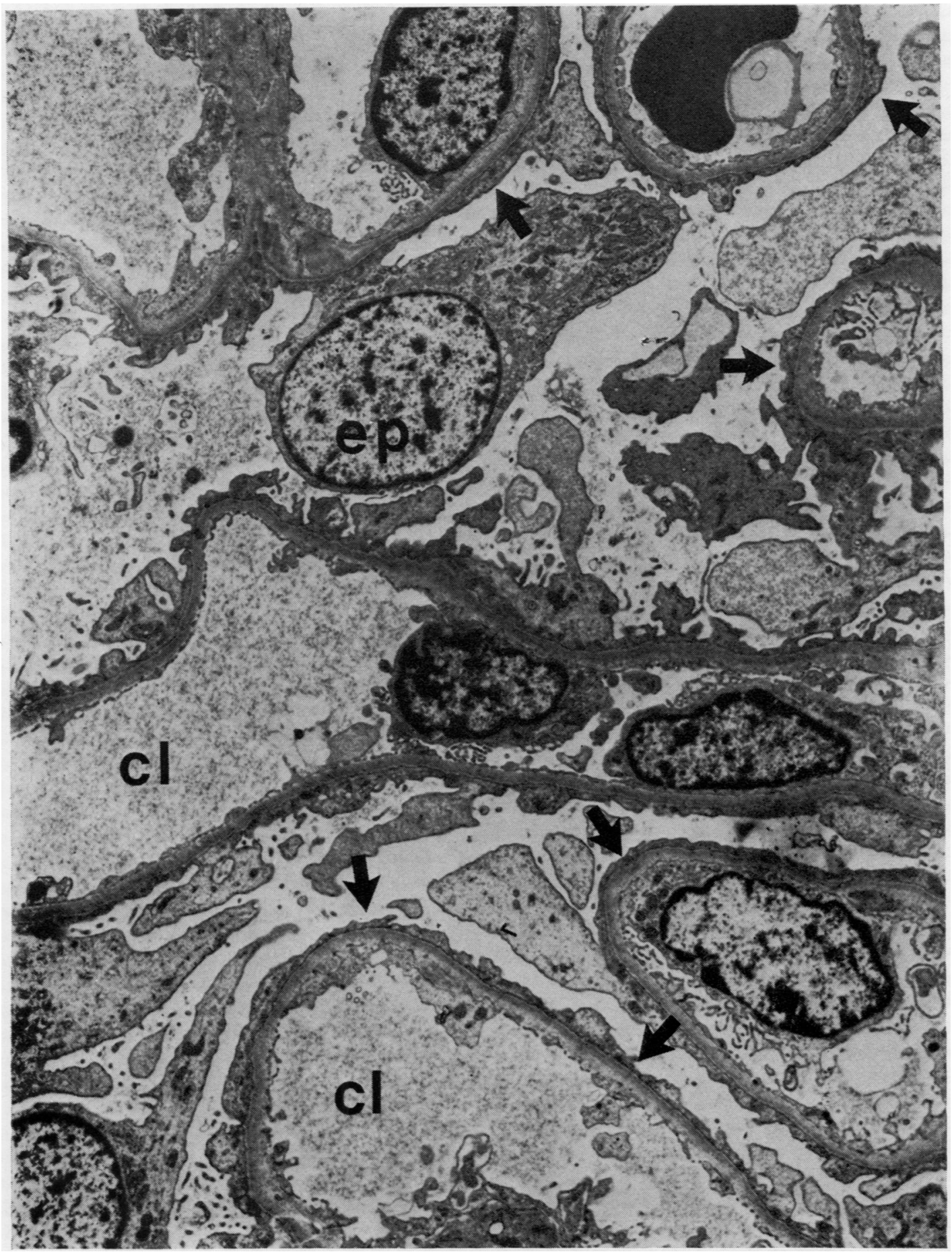

Fig 3 Foot process disease showing fusion of foot processes (arrows) of epithelial cells (ep) along outer borders of normal basement membranes. $c l=$ capillary lumen. TEM $\times 6250$ 


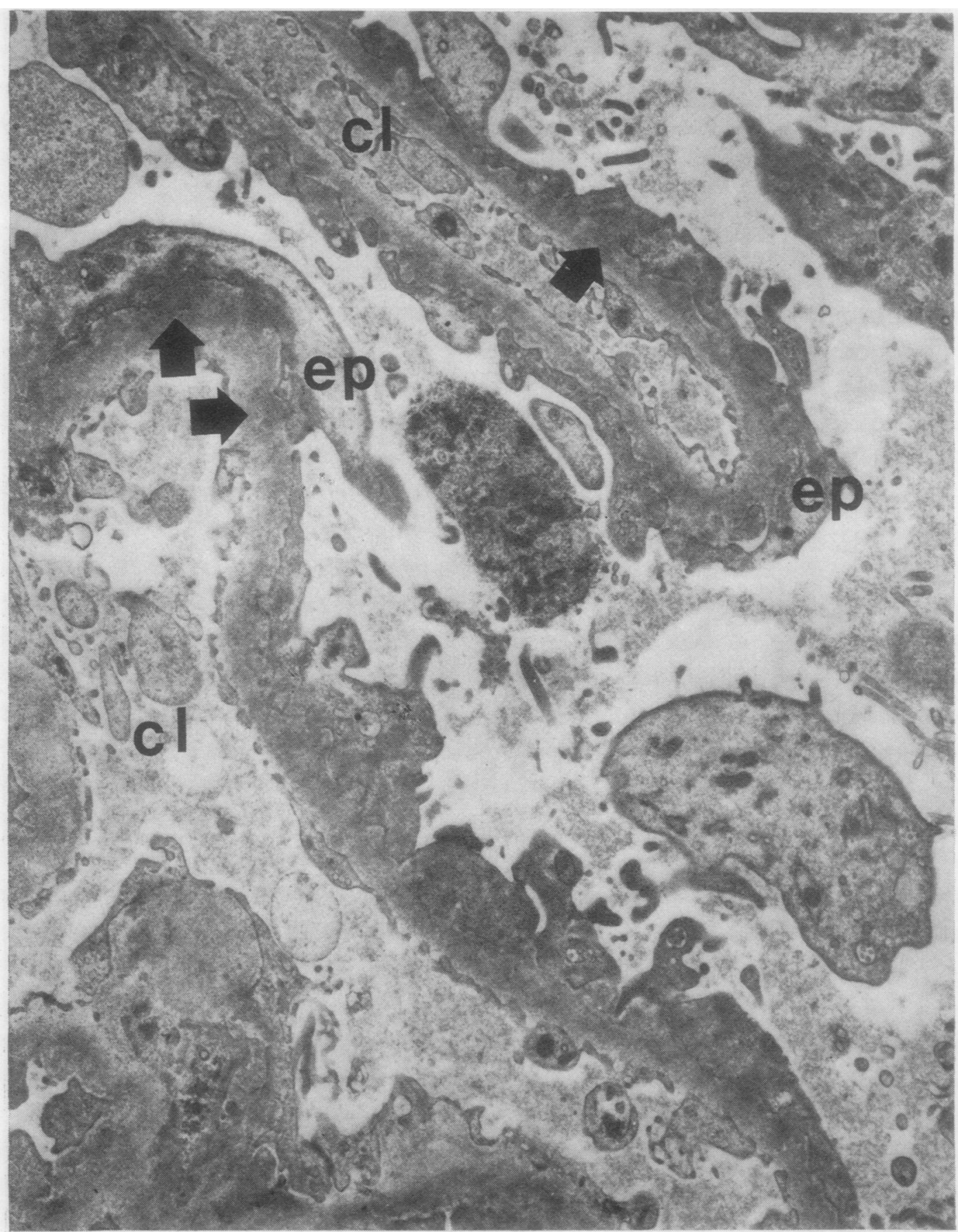

Fig 4 Limited epimembranous immune complex deposition (indicated by arrows) in glomerular basement membranes. Overlying epithelial cells (ep) show extensive foot process fusion. $\mathrm{cl}=$ capillary lumen. $T E M \times 12500$ 


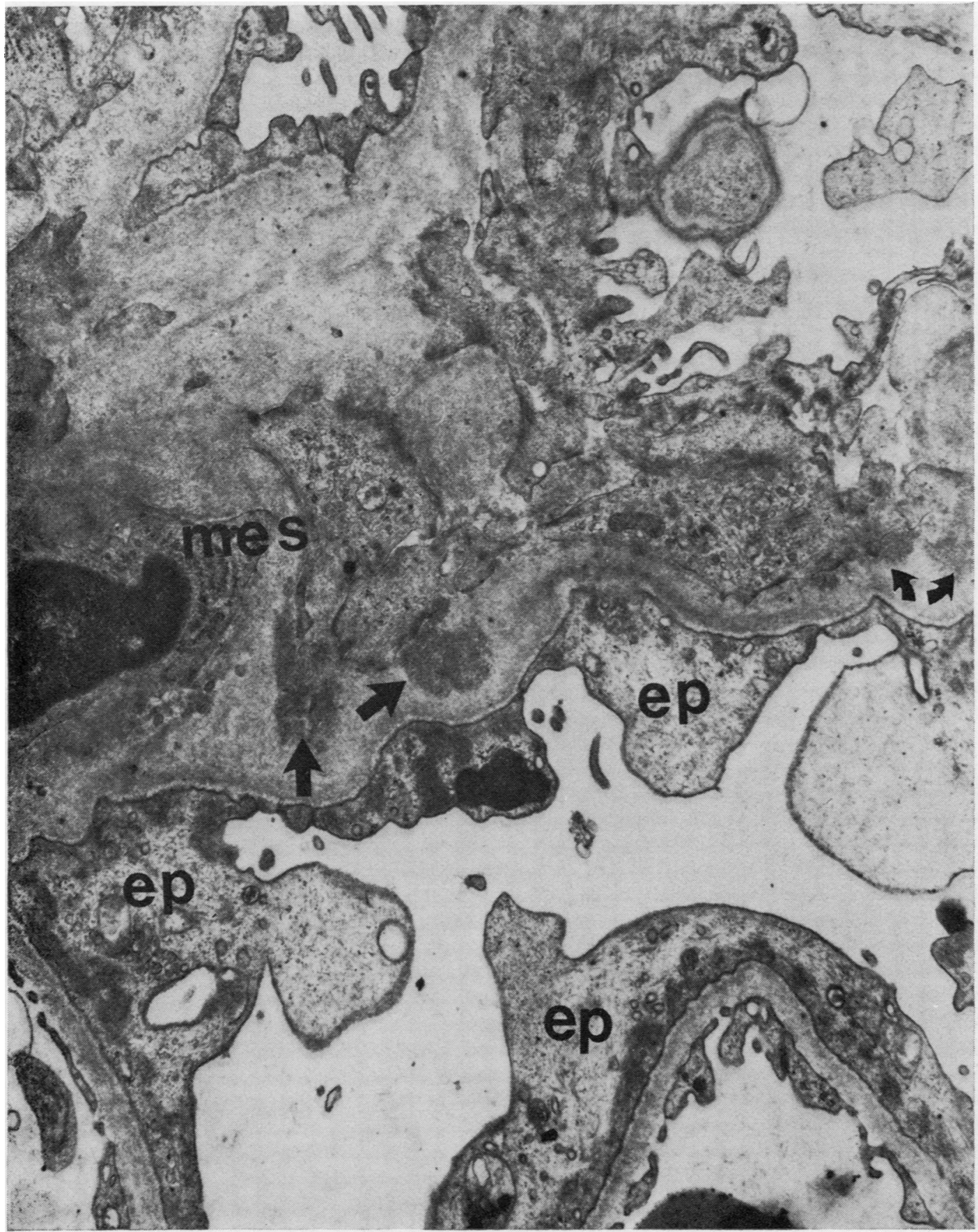

Fig 5 Immune complexes (arrows) within basement membranes in mesangial area (mes). Epithelial cells (ep) show fusion of foot processes. TEM $\times 12500$ 
William Lawler, P. Tarpey, George Williams, E. Joan Acheson, and N. P. Mallick

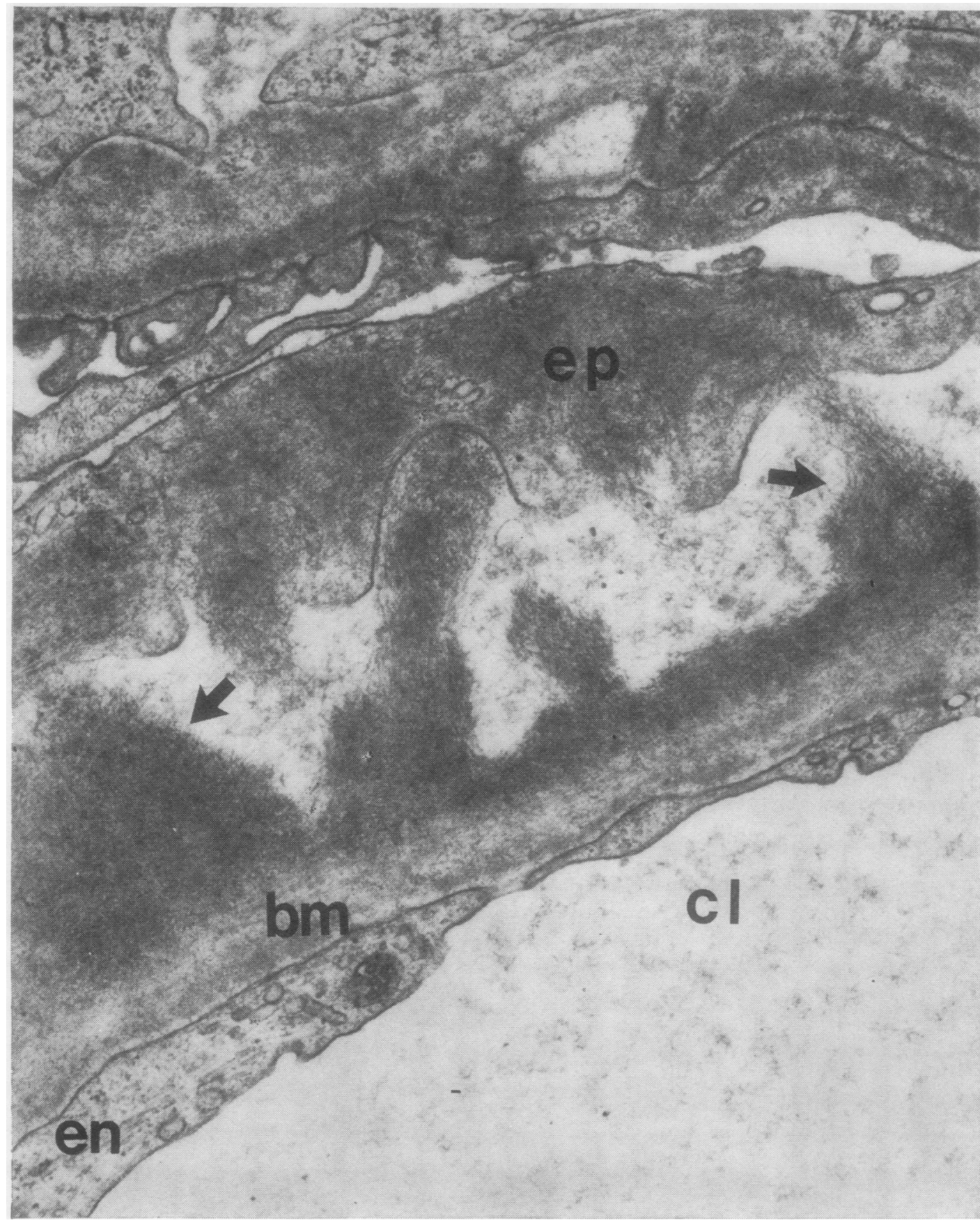

Fig 6 Focal infiltrate of fibrillar amyloid (arrows) which has elevated epithelial cell (ep) from glomerular basement membrane (bm), below which lie the capillary lumen (cl) and lining endothelium (en). TEM $\times 37500$ 


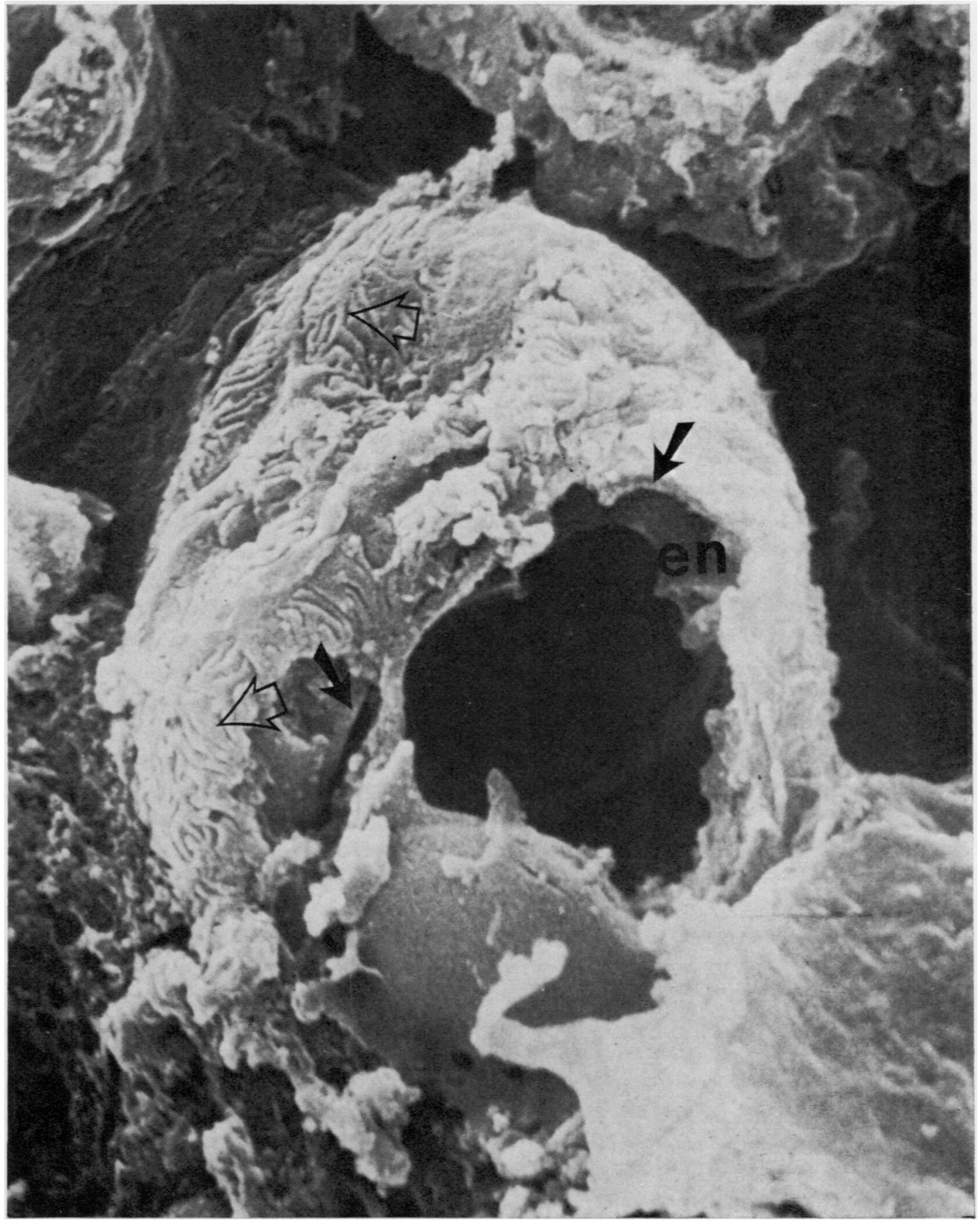

Fig 7 Normal glomerular capillary showing primary and secondary processes (open arrows) of epithelial cells external to glomerular basement membrane (closed arrows), with portion of lining endothelium (en). 


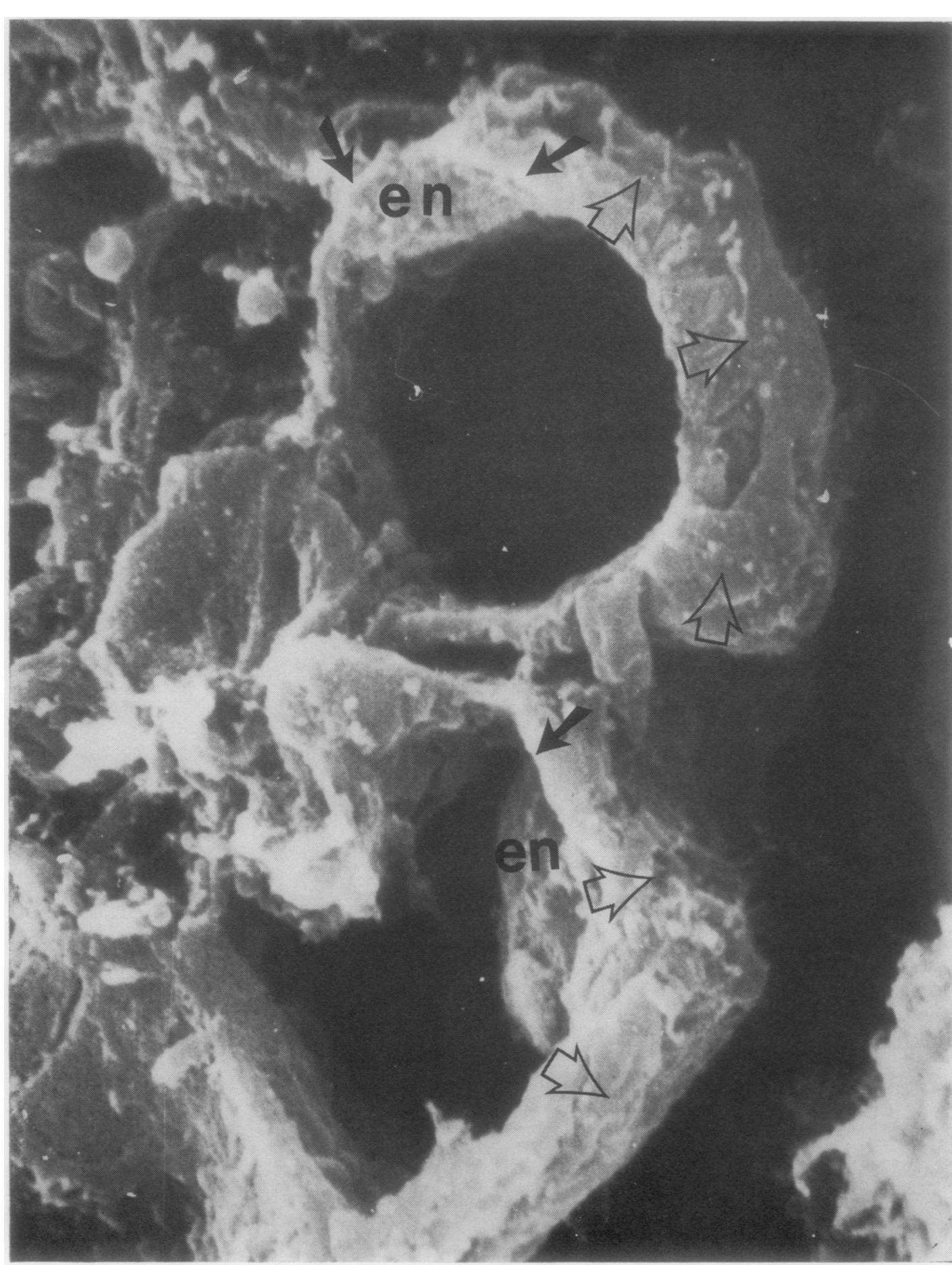

Fig 8 Glomerular capillaries in foot process disease showing loss and fusion of foot processes (open arrows) external to glomerular basement membranes (closed arrows) and portions of endothelial linings (en). SEM $\times 9000$ 


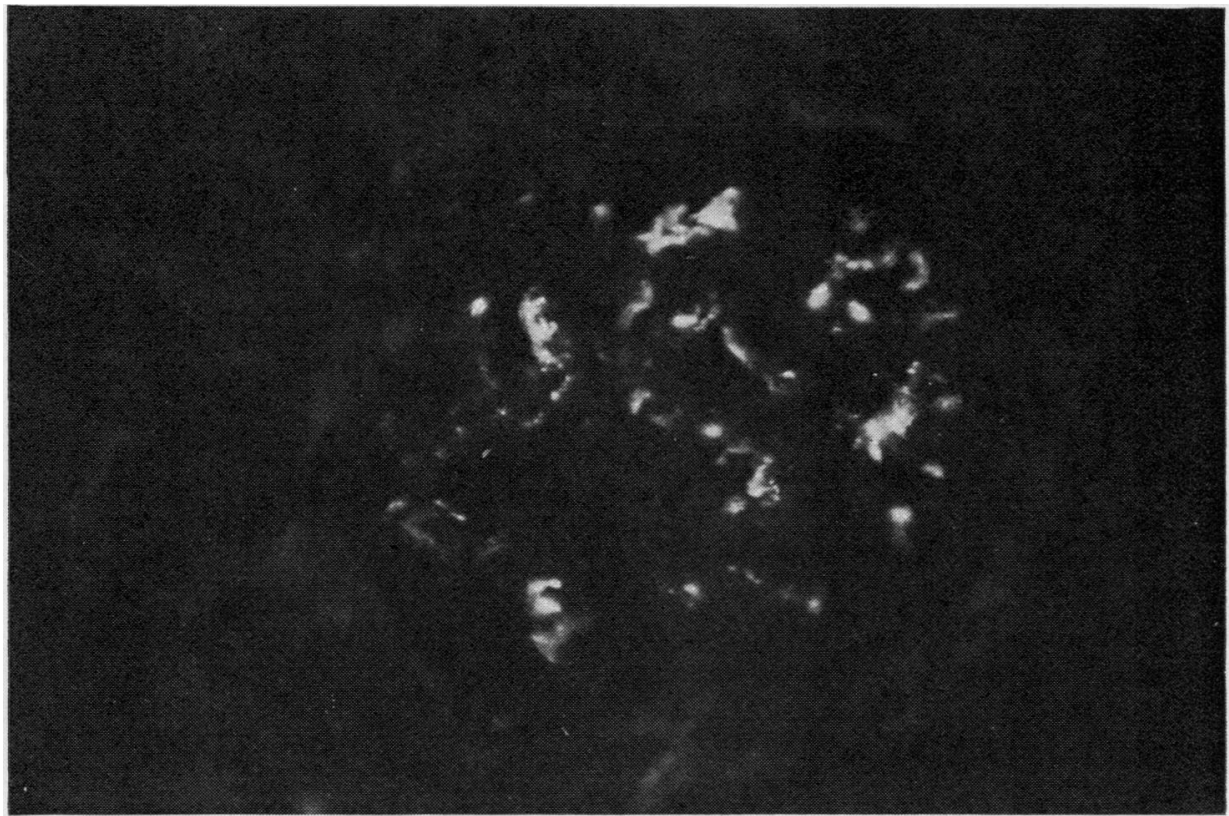

Fig 9 Foci of fluorescent IgM in immune complex deposits in glomerular mesangia. IF $\times 350$

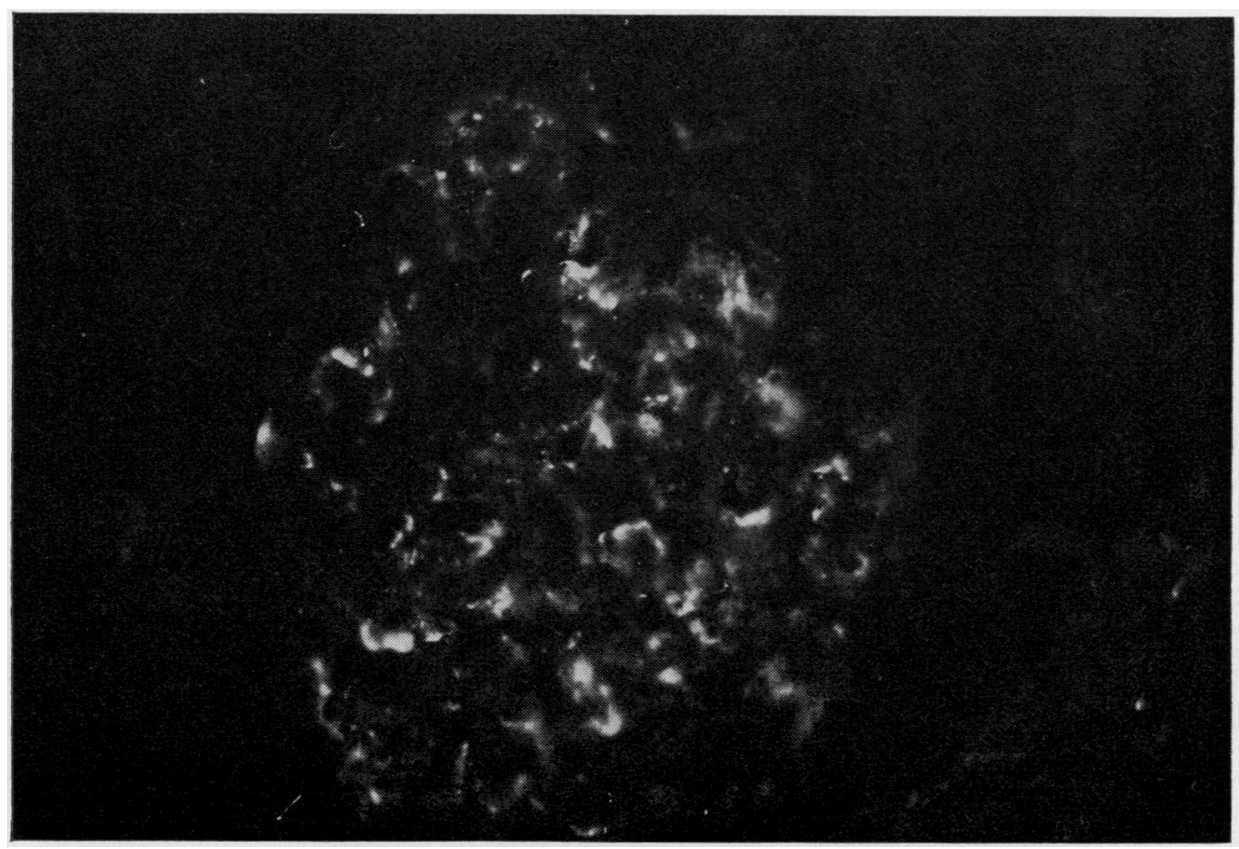

Fig 10 Focal fluorescent deposits of complement $(C 3)$ in immune complexes in basement membrane and mesangia. IF $\times 400$ 


\begin{tabular}{|c|c|c|c|c|c|c|c|}
\hline Case & Sex & $\begin{array}{l}\text { Age at Presentation } \\
(y r)\end{array}$ & $\begin{array}{l}\text { Pathological } \\
\text { Classification } \\
\text { (based on EM and/or } \\
\text { IF findings) }\end{array}$ & Case & Sex & $\begin{array}{l}\text { Age at Presentation } \\
(y r)\end{array}$ & $\begin{array}{l}\text { Pathological } \\
\text { Classification } \\
\text { (based on EM and/or } \\
\text { IF findings) }\end{array}$ \\
\hline 1 & $\mathbf{M}$ & 14 & FPD & 20 & $\mathbf{M}$ & 43 & FPD \\
\hline 2 & $\mathbf{M}$ & 56 & ICD & 21 & $\mathbf{M}$ & 66 & FPD \\
\hline 3 & $\mathbf{M}$ & 46 & FPD & 22 & $\mathbf{M}$ & 60 & FPD \\
\hline 4 & $\mathbf{F}$ & 38 & ICD & 23 & $\mathbf{M}$ & 21 & FPD \\
\hline 5 & $\mathbf{F}$ & 48 & Unclass & 24 & $\mathbf{F}$ & 35 & FPD \\
\hline 6 & $F$ & 56 & ICD & 25 & $\mathbf{M}$ & 13 & ICD \\
\hline 7 & $\mathbf{M}$ & 18 & Unclass & 26 & $\mathbf{F}$ & 21 & ICD \\
\hline 8 & $\mathbf{F}$ & 13 & Unclass & 27 & $\mathbf{F}$ & 38 & ICD \\
\hline 9 & $\mathbf{F}$ & 37 & Unclass & 28 & $\mathbf{M}$ & 58 & 'Amyloid' \\
\hline 10 & $\mathbf{F}$ & 42 & FPD & 29 & $\mathbf{M}$ & 24 & Unclass \\
\hline 11 & $\mathbf{M}$ & 11 & Normal & 30 & $\mathbf{M}$ & 23 & FPD \\
\hline 12 & $\mathbf{F}$ & 48 & FPD & 31 & $\mathbf{M}$ & 26 & ICD \\
\hline 13 & $\mathbf{M}$ & 17 & FPD & 32 & $\mathbf{M}$ & 58 & Unclass \\
\hline 14 & $F$ & 18 & FPD & 33 & $\mathbf{F}$ & 25 & ICD \\
\hline 15 & $\mathbf{M}$ & 50 & Unclass & 34 & $\mathbf{F}$ & 46 & 'Amyloid' \\
\hline 16 & $\mathbf{F}$ & 60 & FPD & 35 & $\mathbf{F}$ & 65 & ICD \\
\hline 17 & $\mathbf{M}$ & 21 & FPD & 36 & $\mathbf{F}$ & 38 & FPD \\
\hline 18 & $\mathbf{M}$ & 59 & FPD & 37 & $\mathbf{M}$ & 18 & FPD \\
\hline 19 & $\mathbf{M}$ & 22 & Unclass & & & & \\
\hline
\end{tabular}

Table I Pathological classification

FPD = foot process disease; ICD = immune complex disease; Unclass = unclassifiable; 'Amyloid' = fibrillar protein present, with a fine structure similar to amyloid

\begin{tabular}{|c|c|c|c|c|c|c|c|c|}
\hline \multirow[t]{2}{*}{ Case } & \multicolumn{4}{|c|}{ On presentation } & \multirow{2}{*}{$\begin{array}{l}\text { Interval between } \\
\text { onset and } \\
\text { Biopsy } \\
\text { (months) }\end{array}$} & \multicolumn{2}{|l|}{ Steroid therapy } & \multirow{2}{*}{$\begin{array}{l}\text { Final } \\
\text { Clinical } \\
\text { Diagnosis }\end{array}$} \\
\hline & Complaint & $\begin{array}{l}\text { Serum } \\
\text { Creatinine } \\
(\mu \mathrm{mol} / \mathrm{l})\end{array}$ & $\begin{array}{l}\text { Proteinuria } \\
(g / \text { dav })\end{array}$ & $\begin{array}{l}\text { Blood Pressure } \\
(\mathrm{mmHg})\end{array}$ & & $\begin{array}{l}\text { Adequate (100 } \\
\text { mg prednisolone } \\
\text { alt die) }\end{array}$ & Response & \\
\hline 1 & NS & 97 & 12 & $140 / 80$ & 6 & Yes & Yes & SRMC \\
\hline 2 & $\operatorname{Pr} U$ & 80 & $5-7$ & $130 / 70$ & 4 & Yes & No & Not MC \\
\hline 3 & NS & 106 & $10-15$ & $140 / 80$ & 3 & Yes & Yes & SRMC \\
\hline 4 & NS & 141 & 7 & $110 / 70$ & 13 & Yes & No & Not MC \\
\hline 5 & NS & 80 & 8 & $110 / 70$ & 120 & No & - & CMC \\
\hline 6 & NS & 88 & $15-35$ & $110 / 70$ & 6 & No & - & CMC \\
\hline 7 & NS & 97 & $16-22$ & $120 / 80$ & 1 & No & - & CMC \\
\hline 8 & NS & 44 & $2 \cdot 5-14$ & $130 / 90$ & 13 & No & - & CMC \\
\hline 9 & NS & 71 & $2-14$ & $120 / 90$ & 9 & Yes & Yes & SRMC \\
\hline 10 & NS & 62 & $5-7$ & $130 / 80$ & 6 & No & - & Not MC \\
\hline 11 & Haemat & 97 & 0 & $110 / 60$ & 13 & No & - & BRH \\
\hline 12 & NS & 80 & $8-20$ & $160 / 85$ & 3 & No & - & CMC \\
\hline 13 & NS & 71 & 3 & $135 / 80$ & 87 & No & - & CMC \\
\hline 14 & PrU & 80 & 14 & $120 / 80$ & 26 & No & - & Not MC \\
\hline 15 & NS & 44 & 22 & $190 / 100$ & 5 & Yes & No & Not MC \\
\hline 16 & NS & 62 & $14-17$ & $150 / 100$ & 1 & No & - & CMC \\
\hline 17 & $\operatorname{Pr} \mathbf{U}$ and $\mathbf{H} / \mathbf{T}$ & 88 & 2 & $140 / 80$ & 9 & No & - & Not MC \\
\hline 18 & NS & 106 & 4-14 & $110 / 70$ & 6 & No & - & CMC \\
\hline 19 & Haemat & 88 & $1.0-1 \cdot 6$ & $160 / 85$ & 18 & No & - & BRH \\
\hline 20 & NS & 203 & $6-14$ & $170 / 120$ & 1 & No & - & CMC \\
\hline 21 & NS & 248 & 14 & $160 / 110$ & 1 & No & - & CMC \\
\hline 22 & NS & 124 & $5-9$ & $150 / 90$ & 2 & No & - & CMC \\
\hline 23 & NS & 88 & $5-13$ & $140 / 90$ & 156 & Yes & Yes & SRMC \\
\hline 24 & PrU & 71 & 4 & $150 / 85$ & 138 & No & - & CMC \\
\hline 25 & NS & 27 & 2.4 & $110 / 70$ & 132 & Yes & Yes & SRMC \\
\hline 26 & PrU & 35 & 3 & $140 / 60$ & 6 & No & - & Not MC \\
\hline 27 & NS & 88 & 9.17 & $130 / 90$ & 4 & Yes & No & Not MC \\
\hline 28 & AlbU and BJ & J 141 & $0 \cdot 6-1.0$ & $160 / 100$ & 1 & No & - & Myeloma \\
\hline 29 & PrU & 71 & $1-1 \cdot 5$ & $120 / 70$ & 3 & No & - & CMC \\
\hline 30 & NS & 88 & $5-13$ & $110 / 75$ & 1 & Yes & Yes & SRMC \\
\hline 31 & PrU & 80 & $2-4$ & $120 / 80$ & 2 & No & - & Not MC \\
\hline 32 & NS & 88 & 3 & $130 / 80$ & 3 & No & - & CMC \\
\hline 33 & NS & 88 & $2 \cdot 5$ & $120 / 70$ & 3 & No & - & CMC \\
\hline 34 & NS & 106 & $10-20$ & $130 / 60$ & 18 & Yes & No & Myeloma \\
\hline 35 & NS & 97 & $1 \cdot 4-8$ & $130 / 80$ & 14 & No & 一 & Not MC \\
\hline 36 & NS & 80 & $9-10$ & $160 / 95$ & 8 & Yes & Yes & SRMC \\
\hline 37 & NS & 35 & $11-19$ & $130 / 60$ & 3 & Yes & Yes & SRMC \\
\hline
\end{tabular}

Table II Clinical data and final clinical diagnoses

$\mathrm{NS}=$ nephrotic syndrome; PrU = proteinuria; Haemat = haematuria; $\mathrm{H} / \mathrm{T}=$ hypertension; AlbU = albuminuria; BJPrU $=$ BenceJones proteinuria; $\mathbf{S R M C}=$ steroid responsive minimal change; $\mathbf{C M C}=$ clinical minimal change; Not $\mathrm{MC}=$ not minimal change clinically; $\mathbf{B R H}=$ benign recurrent haematuria 


\begin{tabular}{lll}
\hline Case & $\begin{array}{l}\text { Diagnosis on } \\
\text { First Biopsy }\end{array}$ & $\begin{array}{l}\text { Diagnosis on Second } \\
\text { Biopsy and Final } \\
\text { Diagnosis }\end{array}$ \\
\hline 4 & ICD & ICD \\
10 & FPD & ICD \\
14 & FPD & ICD \\
15 & Unclass & ICD \\
20 & FPD & FPD \\
27 & ICD & ICD \\
37 & FPD & FPD \\
\hline
\end{tabular}

Table III Diagnoses in cases with repeat biopsies ICD = immune complex disease $; \mathrm{FPD}=$ foot process disease; Unclass $=$ unclassifiable

patients were reviewed; relevant data, including the final clinical diagnoses, are summarized in table II.

They comprised 21 men and 16 women, their ages ranging from 11 to 66 years, with the following presenting symptoms:

Nephrotic syndrome

Proteinuria 6

Haematuria 2

Proteinuria and hypertension 1

Albuminuria and Bence Jones proteinuria 1

ASO titres were recorded on admission in 23 cases; in only one case (11) was it significantly raised $(>300$ Todd units).

Renal function in terms of serum creatinine levels was assessed at presentation in all cases. Values ranged from 27 to $248 \mu \mathrm{mol} / 1(0.3$ to $2.8 \mathrm{mg} / 100$ $\mathrm{ml})$; only four cases $(4,20,21$ and 28$)$ were above the accepted upper limit of normal (133 $\mu \mathrm{mol} / 1 ; 1.5 \mathrm{mg} /$ $100 \mathrm{ml}$ ).

Thirteen patients were given what is now considered adequate steroid therapy, ie, at least $100 \mathrm{mg}$ of prednisolone on alternate days. Of these, eight who responded were classified as steroid responsive minimal change (SRMC). Fifteen patients received inadequate or no steroid therapy but went into spontaneous remission with or without subsequent relapses (clinical minimal change-CMC); 10 failed to respond to steroids or failed to behave clinically as minimal change (not MC); two had benign recurrent haematuria (BRH); and two were cases of myeloma.

\section{REPEAT BIOPSIES}

Repeat biopsies were performed on seven of the 37 cases and related to clinical progress or response to therapy (table III).

Of the two cases (4 and 27) presenting with immune complex disease, one progressed to a severe membranous glomerulopathy and renal failure in the 18 months between biopsies (figs 11 and 12). The other showed no significant structural or immunological change during the inter-biopsy period of 15 months despite clinical deterioration.

Four patients $(10,14,27$, and 37$)$ presented with foot process disease. Two proceeded to moderate deposition of IgM containing complexes within mesangial areas (fig 13) after intervals of 24 and 56 months respectively. Two others registered no structural or immunological change in intervals of 19 and 36 months between biopsies; one of these experienced clinical remission following adjustment of steroid dosage after repeat biopsy.

In one case (15), lack of immunofluorescence data and absence of glomeruli from first biopsy EM fragments prevented classification; repeat biopsy 22 months later disclosed significant IgM and C3 containing complexes within glomerular basement membranes.

\section{DEATH S (table IV)}

Five of the 37 patients studied have died.

Three succumbed to myocardial ischaemia; of these, two with foot process disease showed no histological abnormality of glomeruli in necropsy specimens which were not, however, subjected to IF or EM studies. The third myocardial ischaemic death involved a patient with established immune complex disease, but no necropsy was performed.

A fourth death resulted from massive pulmonary embolus one month after biopsy which had disclosed foot process disease; histology of renal tissue taken at necropsy showed normal glomerular appearances. The fifth death, affecting a patient with glomerular 'amyloid' deposits in his biopsy specimen, resulted from a terminal leukaemic manifestation of myelomatosis.

\section{CLINICOPATHOLOGICAL CORRELATION (table V)}

Clinically, the 37 patients fell into four main groups. Twenty-three fulfilled the clinical criteria of minimal change disease; two had benign recurrent haematuria; two had myelomatosis; and 10 had primary glomerular diseases which failed to respond to adequate steroids and which did not behave clinically as minimal change.

Pathologically, 14 of the 23 cases clinically diagnosed as minimal change showed foot process fusion only on electron microscopy and were therefore classified as 'foot process disease'. Six were unclassifiable because no material was available for electron microscopy. Of the remaining three, one had positive immunofluorescence and complexes on electron microscopy (case 33); the second gave positive immunofluorescence but provided no material for electron microscopy (case 25); the third had electron dense complexes but no glomeruli were available for immunofluorescence (case 6). These three cases were thus classified pathologically as immune complex disease. It is interesting to note 


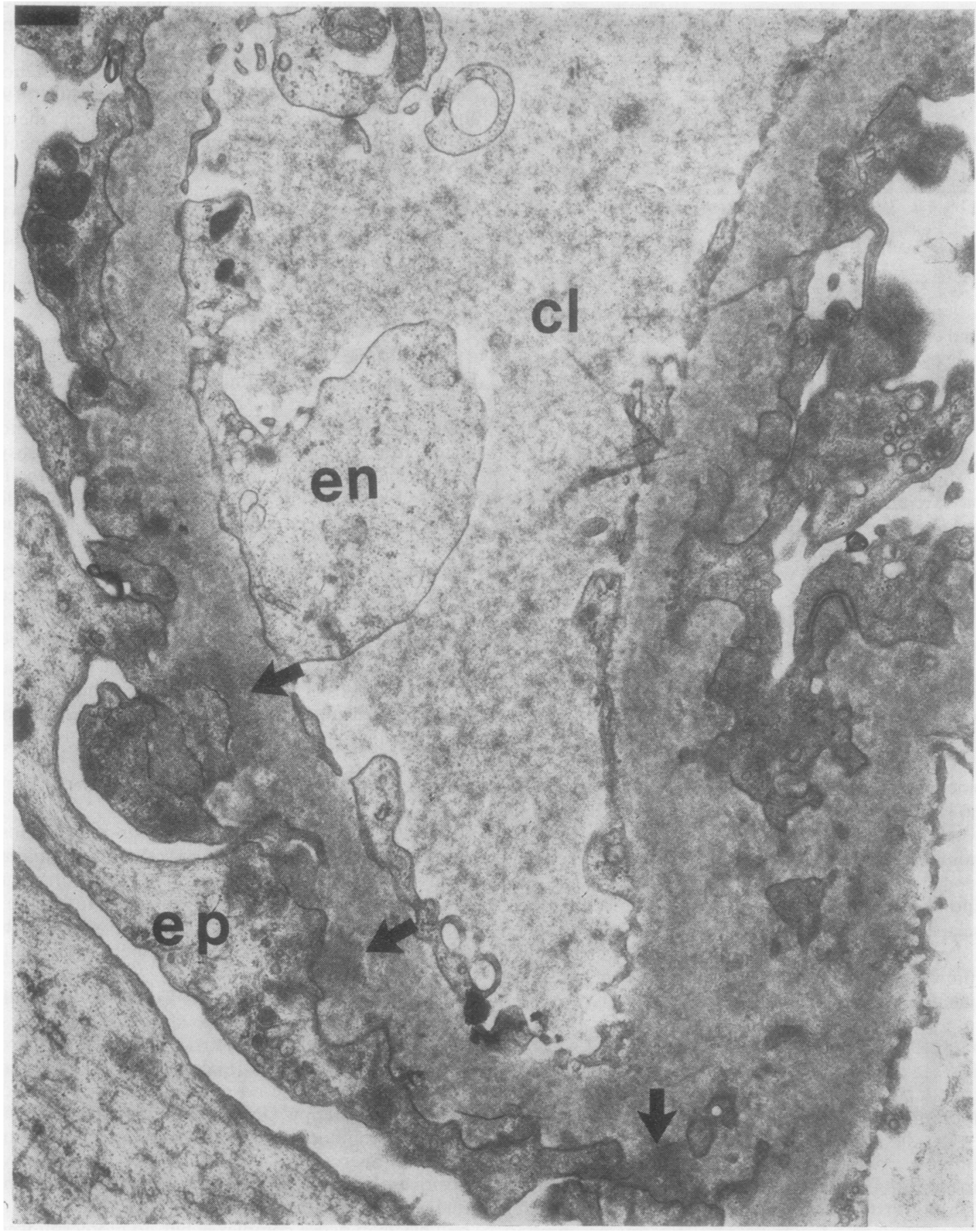

Fig 11 First biopsy from case 4 showing limited immune complex deposition (arrows) along epimembranous aspect of glomerular basement membrane. Epithelial cell (ep) show's foot process fusion; endothelium (en) lines capillary lumen $(c l)($ ff fig 1$) . T E M \times 14250$ 


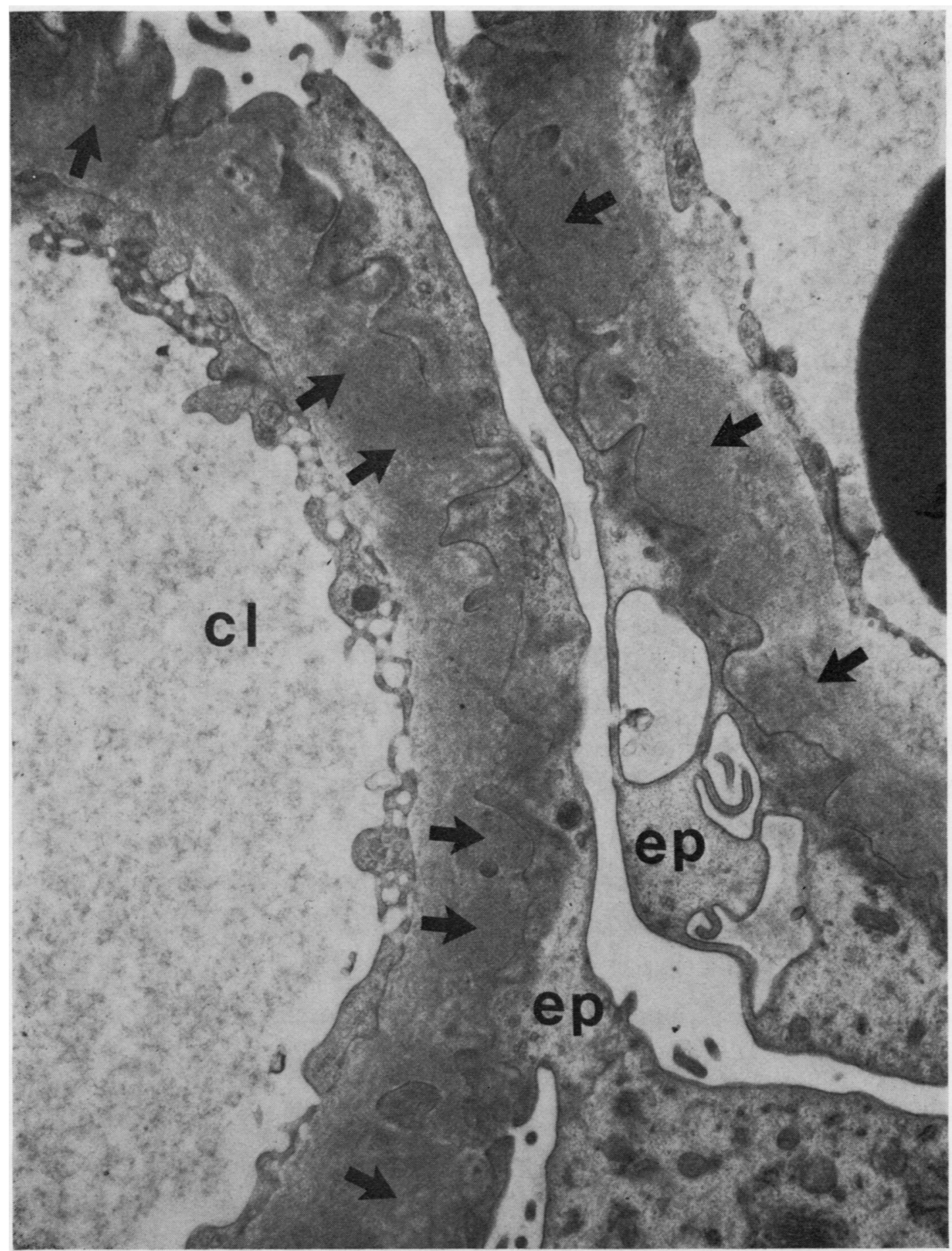

Fig 12 Repeat biopsy from case 4 showing continuous immune complex deposits (arrows) in thickened glomerular basement membranes. Epithelial cells (ep) show extensive foot process fusion; basement membranes are separated from capillary lumina (cl) by fenestrated endothelium (cf figs 1 and 11). TEM $\times 18750$ 


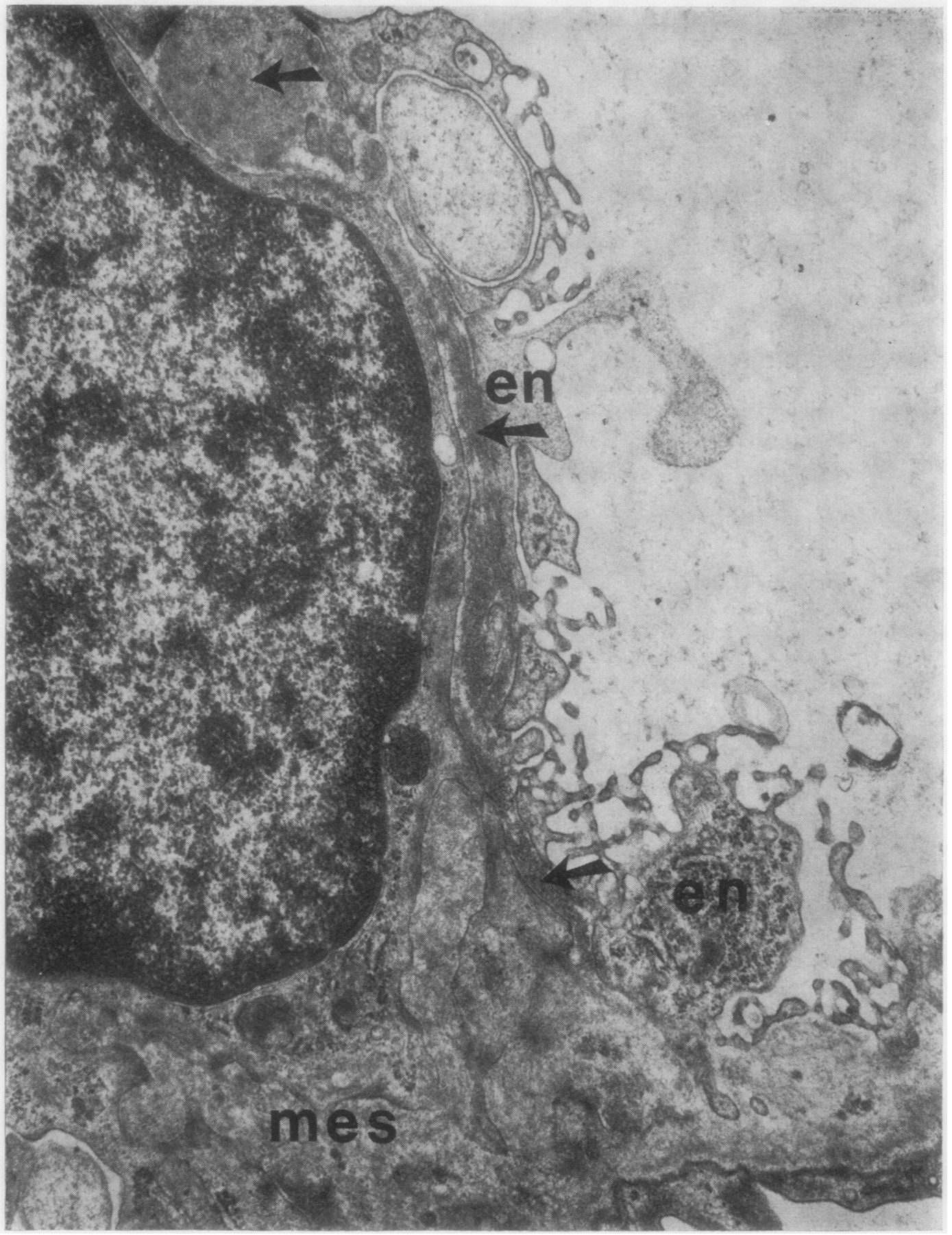

Fig 13 Repeat biopsy from case 10 showing IgM containing complexes (arrow's) in the mesangial areas (mes). Part of a mesangial cell nucleus occupies the upper left. En = capillary endothelium. TEM $\times 25000$ 


\begin{tabular}{rll}
\hline Case & $\begin{array}{l}\text { Renal Biopsy } \\
\text { Diagnosis }\end{array}$ & Cause of Death \\
\hline 2 & ICD & Ischaemic heart disease \\
18 & FPD & Myocardial infarction \\
22 & FPD & Myocardial infarction \\
28 & 'Amyloid' & Acute myelomonocytic leukaemia \\
36 & FPD & Massive pulmonary embolus \\
\hline
\end{tabular}

Table IV Patients who died and the cause of death

that case 6 had a nephrotic syndrome associated with seropositive rheumatoid disease, and that her nephrosis cleared with a change in antirheumatoid therapy which had not included gold treatment. Case 25 had had a transient nephrotic episode at the age of 2 years, and a recurrence in 1971 when aged 13 years. On both occasions remissions occurred spontaneously and rapidly. The biopsy (taken towards the end of the second episode) showed a mild increase in mesangial cells and matrix, possibly representing the late stage of a resolving acute glomerulonephritis. Case 33, who also had a short nephrotic episode with spontaneous and permanent remission, probably also exemplified transient immune complex deposition rather than true minimal change glomerulonephritis.

The two patients with benign recurrent haematuria gave classical clinical histories. In one (case 19), tissue was not available for either immunofluorescence or electron microscopic study. The other (case 11) was biopsied in clinical remission and proved normal electron optically.

Biopsy specimens from both patients with myelomatosis (cases 28 and 34 ) proved negative to immunofluorescence, but electron optically both showed mesangial and subendothelial fibrillar deposits similar to 'amyloid'.

Of the 10 other cases diagnosed clinically as having primary glomerular diseases other than minimal change, six were classified pathologically as immune complex disease, and one (case 15) was unclassifiable because no material was available for electron microscopic or immunofluorescent studies. Repeat biopsy in this instance, however, confirmed the clinical impression of immune complex disease. The remaining three were classified pathologically as foot process disease (cases 10,14, and 17), but, because of their clinical courses, two (10 and 14) were rebiopsied (vide supra) to disclose immune complex disease. The third case (17), a young man who presented in 1970 with asymptomatic proteinuria and mild hypertension, has remained clinically well despite proteinuria and hypertension which have remained at constant levels.

\section{Discussion}

Minimal change glomerulonephritis(lipoid nephrosis, foot process disease, idiopathic nephrotic syndrome) is a well documented clinical and pathological entity. Clinically, the heavy proteinuria or nephrotic syndrome respond favourably to adequate steroid therapy in $95-100 \%$ of cases (Cameron, 1970; Lancet, 1972; Jao et al, 1973; Cameron et al, 1974; Mallick, 1975). It often runs a relapsing course, 40$60 \%$ of patients showing recurrence of proteinuria following steroid withdrawal (Cameron et al, 1974), and spontaneous remissions are common.

Pathologically, the minimal change lesion is

\begin{tabular}{|c|c|c|c|c|c|}
\hline Case & Clinical Diagnosis & Pathological Diagnosis & Case & Clinical Diagnosis & Pathological Diagnosis \\
\hline 1 & SRMC & FPD & 20 & CMC & FPD \\
\hline 2 & Not MC & ICD & 21 & CMC & FPD \\
\hline 3 & SRMC & FPD & 22 & CMC & FPD \\
\hline 4 & Not MC & ICD & 23 & SRMC & FPD \\
\hline 5 & CMC & Unclass & 24 & CMC & FPD \\
\hline 6 & CMC & ICD & 25 & SRMC & ICD \\
\hline 7 & CMC & Unclass & 26 & Not MC & ICD \\
\hline 8 & CMC & Unclass & 27 & Not MC & ICD \\
\hline 9 & SRMC & Unclass & 28 & Myeloma & 'Amyloid" \\
\hline 10 & Not MC & FPD & 29 & CMC & Unclass \\
\hline 11 & BRH & Normal & 30 & SRMC & FPD \\
\hline 12 & CMC & FPD & 31 & Not MC & ICD \\
\hline 13 & CMC & FPD & 32 & CMC & Unclass \\
\hline 14 & Not MC & FPD & 33 & CMC & ICD \\
\hline 15 & Not MC & Unclass & 34 & Myeloma & 'Amyloid' \\
\hline 16 & CMC & FPD & 35 & Not MC & ICD \\
\hline 17 & Not MC & FPD & 36 & SRMC & FPD \\
\hline 18 & CMC & FPD & 37 & SRMC & FPD \\
\hline 19 & BRH & Unclass & & & \\
\hline
\end{tabular}

Table V Clinicopathological correlation

SRMC = steroid responsive minimal change; $\mathbf{C M C}=$ clinical minimal change; Not $\mathbf{M C}=$ not minimal change clinically; $\mathbf{B R H}=$ benign recurrent haematuria; FPD = foot process disease; $I C D=$ immune complex disease; Unclass = unclassifiable; 'Amyloid' = fibrillar protein present, with a fine structure similar to amyloid 
associated with no significant light microscope abnormalities (Robson, 1972; Grishman and Churg, 1973; Jao et al, 1973; Cameron et al, 1974) and with partial or complete fusion of the epithelial cell foot processes at the electron microscope level (Pollak et al, 1968; Spargo and Seymour, 1972; Jao et al, 1973). Many authors now believe that the minimal change lesion is not mediated by immune complex deposition; thus complexes are not seen electron optically, and immunofluorescence is typically negative (Michael et al, 1964; Drummond et al, 1966; Pollak et al, 1968; Hopper et al, 1970; Habib and Kleinknecht, 1971; Berger et al, 1971; MorelMaroger et al, 1972; Hoyer et al, 1972; Muehrcke and Pirani, 1972; Jao et al, 1973; Lewis et al, 1973; Morel-Maroger et al, 1973; Hyman and Burkholder, 1974). In this series, three patients $(6,25$, and 33$)$, in whom a clinical diagnosis of minimal change had been made, showed morphological evidence of immune complex deposition. Probably these cases represent spontaneously resolving immune complex glomerulonephritis rather than true minimal change disease, a situation which is liable to occur in any clinical series of cases of 'minimal change' glomerulopathies.

We have excluded from this series all renal biopsies showing focal and segmental glomerular sclerosis (segmental hyalinosis), an entity which is currently regarded as separate and distinct (Abramowicz et al, 1970; Churg et al, 1970; White et al, 1970; Nagi et al, 1971; Habib and Kleinknecht, 1971; Cameron, 1972; Lancet, 1972; Jao et al, 1973; Berlyne, 1974; Cameron et al, 1974; Jenis et al, 1974; Hyman and Burkholder, 1974). It is appreciated, however, that focal glomerulosclerosis in the early stages affects primarily juxtamedullary glomeruli which may escape a small or superficial biopsy (Churg et al, 1970; White et al, 1970; Lancet, 1972; Jao et al, 1973; Jenis et al, 1974; Hyman and Burkholder, 1974) but the clinical course differs from that of minimal change disease, and rebiopsy may provide the correct diagnosis.

In respect of benign recurrent haematuria, the underlying lesion is a focal proliferative glomerulonephritis (Ross, 1960; Bodian et al, 1965; Ayoub and Vernier, 1965; Ferris et al, 1967; Singer et al, 1968; Cameron, 1972; Heptinstall, 1973; Mallick, 1975).

Ten of our 37 cases $(27 \%)$ showing no significant abnormalities on light microscopy subsequently developed membranous glomerulonephritis. Clinically, these cases $(2,4,10,14,15,17,26,27,31$, and 35 ) have shown a gradual progression of their renal disease and have failed to respond to steroids. Six $(2,4,26,27,31$, and 35$)$ were diagnosed as immune complex disease on electron microscopy of first biopsies, and this was confirmed in two ( 4 and 27 ) by repeat biopsies. In case 15 , neither IF nor EM was performed on the first biopsy, but repeat biopsy confirmed immune complex disease. In three patients? $(10,14$, and 17$)$ diagnosed pathologically as havingo foot process disease, clinical follow-up indicated a음 disease other than minimal change. Repeat biopsiess from two of them (10 and 14) showed conclusived evidence of immune complex disease; repeat biopsyo in the third (17) is under consideration.

In two cases, therefore, repeat biopsies were $\overrightarrow{0}$ necessary to establish the correct pathologica $\rightleftharpoons$ diagnosis. This again raises the question whethero minimal change glomerulonephritis may transform into membranous glomerulonephritis (Hopper et al i 1970). Neither patient, however, behaved clinically ase a subject of minimal change disease, and we agreew with recent authors who state that this transforma tion does not take place (Hopper et al, 1970 Cameron, 1972; Robson, 1972). Possibly these cases represent false negative results related to biopsyz sampling in a disease (membranous glomerulo nephritis), which may not affect all glomerul $\overrightarrow{0}$ equally, particularly in the early stages. Unfor-के tunately, immunofluorescence was not available for assessment of the biopsies in question, a point whicho emphasizes the value of this technique, particularlys when applied to several glomeruli, in distinguishing early membranous from minimal change disease.

\section{Conclusions}

We agree with Muehrcke and Pirani (1972), Mac产 Donald (1973), and Jao et al (1973) that if diagnosis. of glomerular disease by percutaneous biopsy is based solely on light microscope appearances:diseases other than minimal change are likely to b3. overlooked. Accuracy of diagnosis, in structurab terms, requires additional immunofluorescence andB electron microscopic study. Final clinical diagnosiso also requires careful follow-up, and repeat biopsy may be necessary.

We acknowledge with thanks the help of members of the technical staff of the University Department of Pathology with histological preparations.

\section{References}

Abramowicz, M., Barnett, H. L., Edelmann, C. M., Jr.邑 Greifer, I., Kobayashi, O., Arneil, G. C., Barron, B. A.' Gordillo-P., G., Hallman, N., and Tiddens, H. A. (1970) Controlled trial of azathioprine in children with nephrotio syndrome. Lancet, 1, 959-961.

Ayoub, E. M. and Vernier, R. L. (1965). Benign recurren hematuria. Amer.J. Dis. Child., 109, 217-223.

Bencosme, S. A. and Bergman, B. J. (1962). The ultra structure of human and experimental glomerular lesions $\Omega$ Int. Rev. exp. Path. 1. 139-208. 
Berger, J., Yaneva, H., and Hinglais, N. (1971). Immunohistochemistry of glomerulonephritis. Advanc. Nephrol., 1, 11-30.

Berlyne, G. M. (1974). A Course in Renal Diseases, 4th edition, p. 142. Blackwell, Oxford.

Bodian, M., Black, J. A., Kobayashi, N., Lake, B. D., and Shuler, S. E. (1965). Recurrent haematuria in childhood. Quart.J. Med., 34, 359-382.

Cameron, J. S. (1970). Nephrotic syndrome. Brit. med. J., 4, 350-353.

Cameron, J. S. (1972). The natural history of glomerulonephritis. In Renal Disease, edited by D. A. K. Black, 3rd edition, pp. 295-329. Blackwell, Oxford.

Cameron, J. S., Turner, D. R., Ogg, C. S., Sharpstone, P., and Brown, C. B. (1974). The nephrotic syndrome in adults with 'minimal change' glomerular lesions. Quart. J. Med., 43, 461-488.

Churg, J., Habib, R., and White, R. H. R. (1970). Pathology of the nephrotic syndrome in children. Lancet, 1, 12991302.

Drummond, K. N., Michael, A. F., Good, R. A., and Vernier, R. L. (1966). The nephrotic syndrome of childhood: immunologic, clinical and pathologic correlations. J. clin. Invest., 45, 620-630.

Farquhar, M. G., Vernier, R. L., and Good, R. A. (1957a). An electron microscopic study of the glomerulus in nephrosis, glomerulonephritis and lupus erythematosus. $J$. exp. Med., 106, 649-660.

Farquhar, M. G., Vernier, R. L., and Good, R. A. (1957b). Studies on familial nephrosis. II. Glomerular changes observed with the electron microscope. Amer.J. Path., 33, 791-817.

Ferris, T. F., Gorden, P., Kashgarian, M., and Epstein, F. H. (1967). Recurrent hematuria and focal nephritis. New Engl. J. Med., 276, 770-775.

Folli, G., Pollak, V. E., Reid, R. T. W., Pirani, C. L., and Kark, R. M. (1958). Electronmicroscopic studies of reversible glomerular lesions in the adult nephrotic syndrome. Ann. Intern. Med., 49, 775-795.

Grishman, E. and Churg, J. (1973). Pathology of nephrotic syndrome with minimal or minor glomerular changes. In Glomerulonephritis: Morphology, Natural History, and Treatment, edited by P. Kincaid-Smith, T. H. Mathew, and E. L. Becker. Part I, pp. 165-181. Wiley, New York.

Habib, R. and Kleinknecht, C. (1971). The primary nephrotic syndrome of childhood. Path. Ann., 6, 417-474.

Heptinstall, R. H. (1973). The present status of focal glomerulonephritis. In Glomerulonephritis: Morphology, Natural History, and Treatment, edited by P. KincaidSmith, T. H. Mathew, and E. L. Becker, Part I, pp. 287 300. Wiley, New York.

Hopper, J., Ryan, P., Lee, J. C., and Rosenau, W. (1970). Lipoid nephrosis in 31 adult patients: renal biopsy study by light, electron and fluorescence microscopy with experience in treatment. Medicine (Baltimore), 49, 321-341.

Hoyer, J. R., Vernier, R. L., Najarian, J. S., Raij, L., Simmons, R. L., and Michael, A. F. (1972). Recurrence of idiopathic nephrotic syndrome after renal transplantation. Lancet, 2, 343-348.

Hyman, L. R. and Burkholder, P. M. (1974). Focal sclerosing glomerulonephropathy with hyalinosis. J. Pediat., 84, 217225.

Jao, W., Lewy, P., Norris, S. H., Pollak, V. E., and Pirani,
C. L. (1973). Lipoid nephrosis: a reassessment. In Glomerulonephritis: Morphology, Natural History, and Treatment, edited by P. Kincaid-Smith, T. H. Mathew, and E. L. Becker, Part I, pp. 183-198. Wiley, New York.

Jenis, E. H., Teichman, S., Briggs, W. A., Sandler, P., Hollerman, C. E., Calcagno, P. L., Knieser, M. R., Jensen, G. E., and Valeski, J. E. (1974). Focal segmental glomerulosclerosis. Amer.J. Med., 57, 695-705.

Lancet (1972). Leading article. Focal glomerulosclerosis. Lancet, 2, 367.

Lewis, E. J., Kallen, R. J., and Rowe, D. S. (1973). Glomerular localisation of IgE in lipoid nephrosis. (Letter). Lancet, 1, 1395.

MacDonald, M. K. (1973). Electron microscopy in the classification of glomerulonephritis. In Glomerulonephritis: Morphology, Natural History, and Treatment, edited by $\mathrm{P}$. Kincaid-Smith, T. H. Mathew, and E. L. Becker, Part I, pp. 111-142. Wiley, New York.

Mallick, N. P. (1975). Immunology of renal disease. In Immunology in Medical Practice, edited by G. Taylor, pp. 215-234. Saunders, London.

Michael, A. F., Drummond, K. N., Vernier, R. L., and Good, R. A. (1964). The immunologic basis of renal disease. Pediat. clin. N. Amer., 11, 685-721.

Morel-Maroger, L., Adam, C., and Richet, G. (1973). The value of immunofluorescence in the diagnosis of glomerulonephritis not related to systemic diseases. In Glomerulonephritis: Morphology, Natural History, and Treatment, edited by P. Kincaid-Smith, T. H. Mathew, and E. L. Becker, Part I, pp. 81-110. Wiley, New York.

Morel-Maroger, L., Leathem, A., and Richet, G. (1972). Glomerular abnormalities in nonsystemic diseases. Amer. J. Med., 53, 170-184.

Movat, H. Z. and McGregor, D. D. (1959). The fine structure of the glomerulus in membranous glomerulonephritis (lipoid nephrosis) in adults. Amer. J. clin. Path., 32, 109127.

Muehrcke, R. C. and Pirani, C. L. (1972). Renal biopsy: an adjunct in the study of kidney disease. In Renal Disease, edited by D. A. K. Black, 3rd edition, p. 128. Blackwell, Oxford.

Nagi, A. H., Alexander, F., and Lannigan, R. (1971). Light and electron microscopical studies of focal glomerular sclerosis. J. clin. Path., 24, 846-850.

Pollak, V. E., Rosen, S., Pirani, C. L., Muehrcke, R. C., and Kark, R. M. (1968). Natural history of lipoid nephrosis and of membranous glomerulonephritis. Ann. intern. Med., 69, 1171-1196.

Robson, J. S. (1972). The nephrotic syndrome. In Renal Disease, edited by D. A. K. Black, 3rd edition, pp. 331366. Blackwell, Oxford.

Ross, J. H. (1960). Recurrent focal nephritis. Quart. J. Med., 29, 391-406.

Singer, D. B., Hill, L. L., Rosenberg, H. S., Marshall, J., and Swenson, R. (1968). Recurrent haematuria in childhood. New Engl.J. Med., 279, 7-12.

Spargo, B. H. and Seymour, A. E. (1972). The value of electron microscopy in the study of glomerular disease. In Renal Disease, edited by D. A. K. Black, pp. 155-186. Blackwell, Oxford.

White, R. H. R., Glasgow, E. F., and Mills, R. J. (1970). Clinicopathological study of the nephrotic syndrome in childhood. Lancet, 1, 1353-1359. 